\title{
Melting Curve and Phase Relations of Fe-Ni Alloys Implications for the Earth's Core Composition
}

Torchio, R.; Boccato, S.; Miozzi, F.; Rosa, A. D.; Ishimatsu, N.; Kantor, Innokenty; Sévelin-Radiguet, N.; Briggs, R.; Meneghini, C.; Irifune, T.

Total number of authors:

11

Published in:

Geophysical Research Letters

Link to article, DOI:

10.1029/2020GL088169

Publication date:

2020

Link back to DTU Orbit

Citation (APA):

Torchio, R., Boccato, S., Miozzi, F., Rosa, A. D., Ishimatsu, N., Kantor, I., Sévelin-Radiguet, N., Briggs, R., Meneghini, C., Irifune, T., \& Morard, G. (2020). Melting Curve and Phase Relations of Fe-Ni Alloys: Implications for the Earth's Core Composition. Geophysical Research Letters, 47(14), e2020GL088169.

https://doi.org/10.1029/2020GL088169

\section{General rights}

Copyright and moral rights for the publications made accessible in the public portal are retained by the authors and/or other copyright owners and it is a condition of accessing publications that users recognise and abide by the legal requirements associated with these rights.

- Users may download and print one copy of any publication from the public portal for the purpose of private study or research.

- You may not further distribute the material or use it for any profit-making activity or commercial gain

- You may freely distribute the URL identifying the publication in the public portal 


\section{Geophysical Research Letters}

\author{
RESEARCH LETTER \\ 10.1029/2020GL088169 \\ Key Points: \\ - Melting curve and phase diagram of \\ Fe-20wt $\% \mathrm{Ni}$ and $\mathrm{Fe}-36$ wt $\% \mathrm{Ni}$ have \\ been investigated by in situ $\mathrm{X}$-ray \\ absorption up to $120 \mathrm{GPa}$ and $3500 \mathrm{~K}$ \\ - Ni alloying shifts the hcp/fcc/liquid \\ triple point to higher pressures and \\ temperatures \\ - The triple point for $\mathrm{Fe}-10 \mathrm{wt} \% \mathrm{Ni}$ is \\ predicted to be around $135 \mathrm{GPa}$ and \\ $3800 \mathrm{~K}$ fixing new benchmarks for \\ the Earth's core composition
}

Supporting Information:

- Supporting Information S1

Correspondence to:

R. Torchio,

torchio@esrf.fr

Citation:

Torchio, R., Boccato, S., Miozzi, F., Rosa, A. D., Ishimatsu, N., Kantor, I., et al. (2020). Melting curve and phase relations of Fe-Ni alloys: Implications for the Earth's core composition. Geophysical Research Letters, 47, e2020GL088169. https://doi.org/ 10.1029/2020GL088169

Received 27 MAR 2020 Accepted 12 JUN 2020 Accepted article online 18 JUN 2020

C2020. American Geophysical Union. All Rights Reserved.

\section{Melting Curve and Phase Relations of Fe-Ni Alloys: Implications for the Earth's Core Composition}

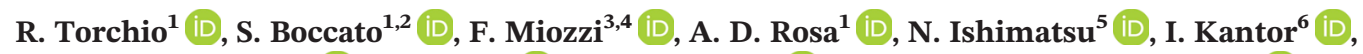

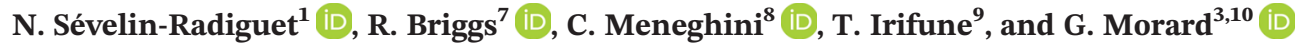 \\ ${ }^{1}$ European Synchrotron Radiation Facility, Grenoble, France, ${ }^{2}$ Now at Sorbonne Université, Muséum National d' Histoire \\ Naturelle, UMR CNRS 7590, Institut de Minéralogie, de Physique des Matériaux, et de Cosmochimie (IMPMC), Paris, \\ France, ${ }^{3}$ Sorbonne Université, Muséum National dHistoire Naturelle, UMR CNRS 7590, Institut de Minéralogie, de \\ Physique des Matériaux, et de Cosmochimie (IMPMC), Paris, France, ${ }^{4}$ Now at Dipartimento di Scienze della Terra, \\ Universitá degli Studi di Milano, Milano, Italy, ${ }^{5}$ Graduate School of Advanced Science and Engineering, Hiroshima \\ University, Hiroshima, Japan, ${ }^{6}$ Institut for Fysik, Danmarks Tekniske Universitet, Kongens Lyngby, Denmark, ${ }^{7}$ Lawrence \\ Livermore National Laboratory, Livermore, CA, USA, ${ }^{8}$ Department of Sciences, Roma Tre University of Rome, Rome, \\ Italy, ${ }^{9}$ Geodynamics Research Center, Ehime University, Matsuyama, Japan, ${ }^{10}$ Université Grenoble Alpes, Université \\ Savoie Mont Blanc, CNRS, IRD, IFSTTAR, ISTerre, Grenoble, France
}

Abstract Nickel is the second most abundant element in the Earth's core. However, the properties of Fe-Ni alloys are still poorly constrained under planetary cores conditions, in particular concerning the effect of Ni on the melting curve of Fe. Here we show that Ni alloying up to $36 \mathrm{wt} \%$ does not affect the melting curve of Fe up to $100 \mathrm{GPa}$. However, Ni strongly modifies the hexagonal-closed-packed/facecentered-cubic (hcp/fcc) phase boundary, pushing the hcp/fcc/liquid triple point of Fe-20wt\%Ni to higher pressures and temperatures. Our results allow constraining the triple point for $\mathrm{Fe}-10 \mathrm{wt} \% \mathrm{Ni}$, a composition relevant for the Earth interior, and point out a decrease of the melting temperature at core-mantle boundary by $400 \mathrm{~K}$ with respect to pure Fe. A lower amount of light elements than previously predicted is thus required to reduce the crystallization temperature of core materials below that of a peridotitic lower mantle, in better agreement with geochemical observations.

Plain Language Summary The Earth's core is believed to be composed of Fe alloyed with $\mathrm{Ni}$ and several lighter elements. In this paper, we investigate the effect of $\mathrm{Ni}$ alloying on the Fe phase diagram. The main effect of $\mathrm{Ni}$ addition is to enlarge the pressure/temperature stability domain of the face-centered-cubic (fcc) phase with respect to the hexagonal-closed-packed (hcp) phase and to shift the hcp/fcc/liquid triple point to higher pressures and temperatures. This implies a depression of the melting curve of Fe-Ni alloys by around $400 \mathrm{~K}$ at mantle boundary conditions, at Ni concentrations pertinent for the Earth interior. This consequently decreases the temperature of the liquidus for Fe alloys constituting the Earth's core, in turn implying a reduced amount of light elements than previously predicted.

\section{Introduction}

Constraining the thermal profile of planetary cores is mandatory to model their dynamics, from the generation of the magnetic field to the mechanism of differentiation. Melting curves of materials constituting their interior provide a first constrain on their thermal profile. For instance, in the Earth, the crystallization temperature of liquid iron alloys, forming the solid inner core, represents an anchoring point for the geotherm through the Earth's core.

Nickel is the second most abundant element in planetary cores, after iron. However, as these two metals have a similar atomic number, the effects of nickel on the properties of iron are often assumed to be small in comparison to those of light elements (i.e., C, O, S, Si, and H) (Poirier, 1994). Based on cosmochemical models and studies on iron meteorites, the Earth's core is believed to be composed of iron alloyed with 5-15 wt\% of Ni (and other light elements) (Birch, 1952; Hirose et al., 2013), while iron meteorites have been found to contain up to $35 \mathrm{wt} \%$ of $\mathrm{Ni}$ (Buchwald, 1975).

While numerous investigations on pure Fe phase diagram under extreme conditions of pressure and temperature have been conducted, only few have been dedicated to Fe-Ni alloys. In particular, measurements 
of their melting curves are very scarce. To the best of our knowledge, there is only one study dedicated to the melting curve of the Fe-Ni alloy with $10 \mathrm{wt} \%$ of nickel, using Synchrotron Mössbauer Spectroscopy (SMS) in the LH-DAC (Zhang et al., 2016). In this study, no obvious effect of Ni was observed on the melting temperature of Fe up to $125 \mathrm{GPa}$.

Solid phase relations for Fe-Ni alloys at concentrations between 5 and $50 \mathrm{wt} \%$ of Ni have been previously investigated (Dubrovinsky et al., 2007; Huang et al., 1988, 1992; Komabayashi et al., 2012; Kuwayama et al., 2008; Lin et al., 2002; Mao et al., 2006) up to $300 \mathrm{GPa}$ and $3000 \mathrm{~K}$, showing that Ni alloying enlarges the facecentered-cubic (fcc) phase stability to higher pressures $(P)$ and lower temperatures $(T)$ with increasing $\mathrm{Ni}$ content. Ni alloying has also proved to dramatically increase the strength of pure Fe (Reagan et al., 2018). On the other hand, the Fe equation of state (Mao et al., 1990) and c/a ratio of the hexagonal-closed-packed (hcp) phase at high $P$ and high $T$ (Komabayashi et al., 2012; Lin et al., 2002; Sakai et al., 2014) have shown to remain practically unaffected. These studies have contributed to the formulation of hypothesis regarding the properties and structure of the Earth's inner core that include several extrapolations and assumptions, one of those being the effect of $\mathrm{Ni}$ addition on the melting curve of $\mathrm{Fe}$.

The purpose of this study is to clarify how Ni alloying affects the Fe phase diagram and in particular its melting curve. The melting temperature of this end-member is mandatory to constrain the liquidus shape.

\section{Experimental Methods}

Fe-Ni samples with 20 and 36 wt\% of Ni were compressed and heated in Diamond Anvil Cells (DACs) equipped with nanocrystalline diamond anvils (Rosa et al., 2019) in order to avoid diamond Bragg peaks. The culet sizes range was from 150 to 400 microns in diameter. The sample chamber was made of preindented rhenium gaskets with holes of 70-150 microns in diameter, and the sample was placed between two $\mathrm{KCl}$ disks, previously dried in vacuum oven, used both as thermal insulator and pressure transmitting medium. The samples were polycrystalline foils by Goodfellow with initial thickness of $6 \mu \mathrm{m}$ (Fe20wt\% Ni) and $8 \mu \mathrm{m}(\mathrm{Fe}-36 \mathrm{wt} \% \mathrm{Ni})$.

Fe K-edge (7.112 KeV) and Ni K-edge (8.333 KeV) EXAFS (Extended X-ray Absorption Fine Structure) measurements were performed at the energy dispersive beamline ID24 at the European Synchrotron Radiation Facility (ESRF) (Pascarelli et al., 2016). The X-ray spot size on the sample was $4 \times 5 \mu \mathrm{m}^{2}$ FWHM (Full Width at Half Maximum).

The laser heating facility at ID24 (Kantor et al., 2018) allows to measure EXAFS spectra of a compressed sample while it is heated from both sides of the DAC. The temperature is measured by spectral radiometry also from both sides. The heating lasers are two infrared (IR) CW Nd:YAG fiber lasers (IPG photonics) with $\lambda=1064 \mathrm{~nm}$, focused to a spot size of around $20 \mu \mathrm{m}$ diameter on the sample. Once the sample is compressed to the desired pressure, a triggering system allows to launch the laser heating, the temperature measurement, and the X-ray acquisition simultaneously, according to the scheme described in Boccato et al. (2017). The error over the measured temperature is chosen as the maximum between the error obtained from the sliding two-colors fit (Benedetti \& Loubeyre, 2004; Giampaoli et al., 2018) and the difference in the temperature measurements from the two sides of the DAC. Temperature uncertainties are typically within $10 \%$ of the measured temperature but can reach $14 \%$ at low temperature because of low signal-tonoise ratio of the emission signal. The pressure was measured using the ruby fluorescence (Dewaele et al., 2008) before and after the heating run; the pressure uncertainty typically accounts for around $10 \%$ of the measured pressure. Thermal pressure was estimated as described in Morard et al. (2018). Further details on the experimental procedure can be found in the supporting information.

\section{Results and Discussion}

Solid-solid and solid-liquid relations were investigated for Fe-Ni with $\mathrm{Ni}$ at 20 and $36 \mathrm{wt} \%$ in the $0-120 \mathrm{GPa}$ and 300-3500 K range.

At ambient conditions, Fe-20wt\%Ni is stable with bcc (body-centered-cubic) structure, like pure iron. Up to $12 \mathrm{GPa}$, all EXAFS oscillations shift to higher energies as a consequence of the interatomic distance compression (see Figure 1, left). Above $12 \mathrm{GPa}$, the bcc-to-hcp structural transition starts and is well visible in the transformations of the XANES (X-ray Absorption Near Edge Structure) features and EXAFS oscillations 

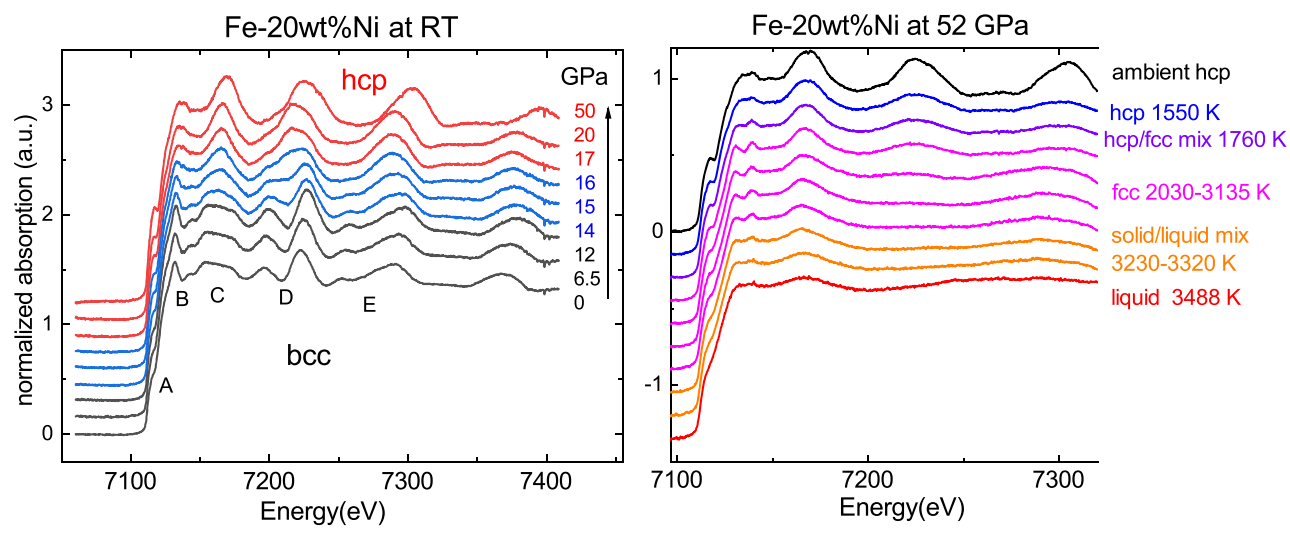

Figure 1. Left: selection of EXAFS spectra of Fe-20wt\%Ni acquired under pressure and room temperature. The data are shifted in vertical for clarity. The bcc-to-hcp structural transition starts above $12 \mathrm{GPa}$ (blue lines), and it is completed at $17 \mathrm{GPa}$ (red lines). Right: example of heating run performed at a starting pressure of $52 \mathrm{GPa}$. A selection of EXAFS spectra has been chosen to show the subsequent transitions from hcp (black and blue line) to fcc (pink) to the liquid phase (red). The data are shifted in vertical for clarity (the temperature increases downward).

(A-E features). The transition is completed at $17 \mathrm{GPa}$, and above this pressure, only the energy shift due to compression is observed. The transition pressure and width are similar to that of pure iron, reported to occur around $13 \mathrm{GPa}$, with width variations depending on the transmitting medium (Barge \& Boehler, 1990).

Upon heating, hcp Fe-20wt\%Ni transforms into the fcc structure. The hcp to fcc transition is hard to observe in the EXAFS region because the oscillations are very similar for the two phases (see Figure 1, right panel). This is not surprising since the hcp and fcc structures differ only in their stacking sequence of the planes. However, significant modifications occur in the XANES region, as it is shown in the left panel of Figure 2. Temperature slightly modifies the XANES of the hcp structure. The subsequent transition to the fcc structure shows up in the appearance of a two peaks structure (B) and flattening of the shoulder slope (A). The same transformation was observed at different pressures from 15 to $100 \mathrm{GPa}$. However, below $40 \mathrm{GPa}$, it is not possible to measure the transition temperature as the emission is too low for spectro-radiometry. At $70 \mathrm{GPa}$, the example shown in Figure 2, the transition starts at $1990 \mathrm{~K}$ and is completed at $2210 \mathrm{~K}$. A similar behavior has been observed in pure iron for the T-induced hcp-fcc transition (Morard et al., 2018). Fe-36wt\%Ni was found in the fcc structure at ambient conditions and in all the explored $\mathrm{P} / \mathrm{T}$ range before melting.
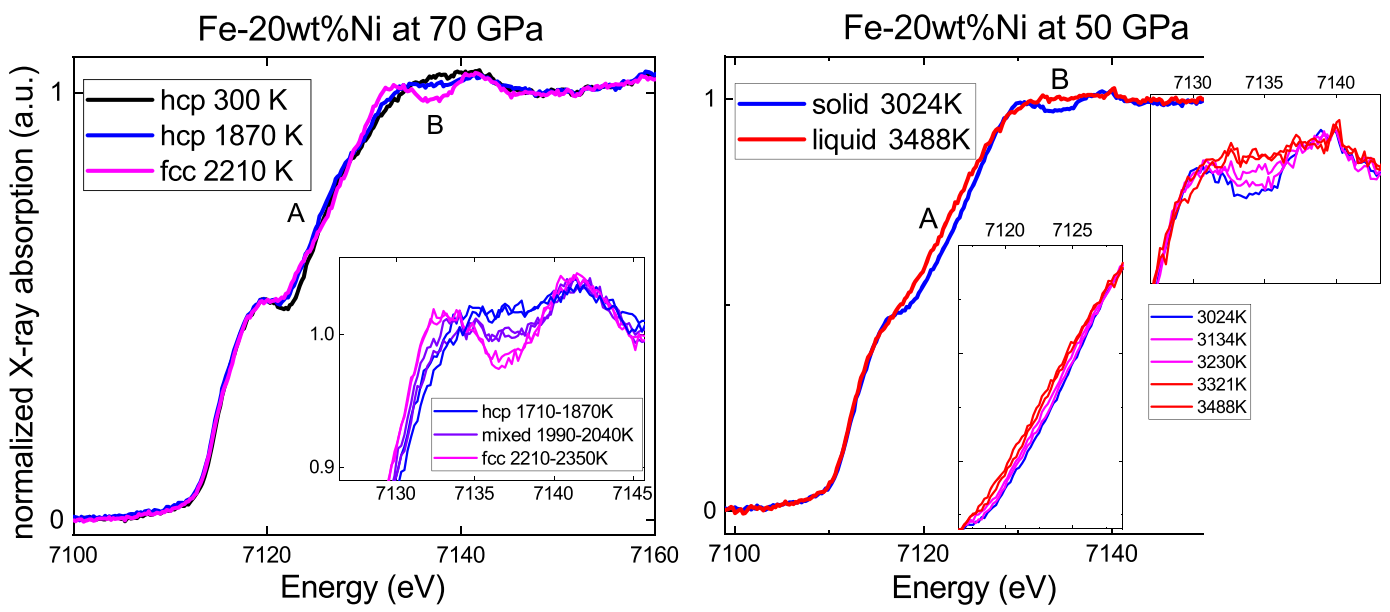

Figure 2. Left: selection of XANES spectra showing the temperature-induced hcp-fcc phase transition in Fe-20wt\%Ni at $70 \mathrm{GPa}$. The black, blue, and pink solid lines represent the XANES signal from the hcp phase at room temperature, the hcp phase at high temperature, and the fcc phase, respectively. The inset shows spectra of mixed hcp-fcc phases (violet lines) along the transition. Right: selection of XANES spectra showing the melting of Fe-20wt\%Ni at $50 \mathrm{GPa}$. The two smaller panels on the right are zooms over the regions where the modifications occur. 


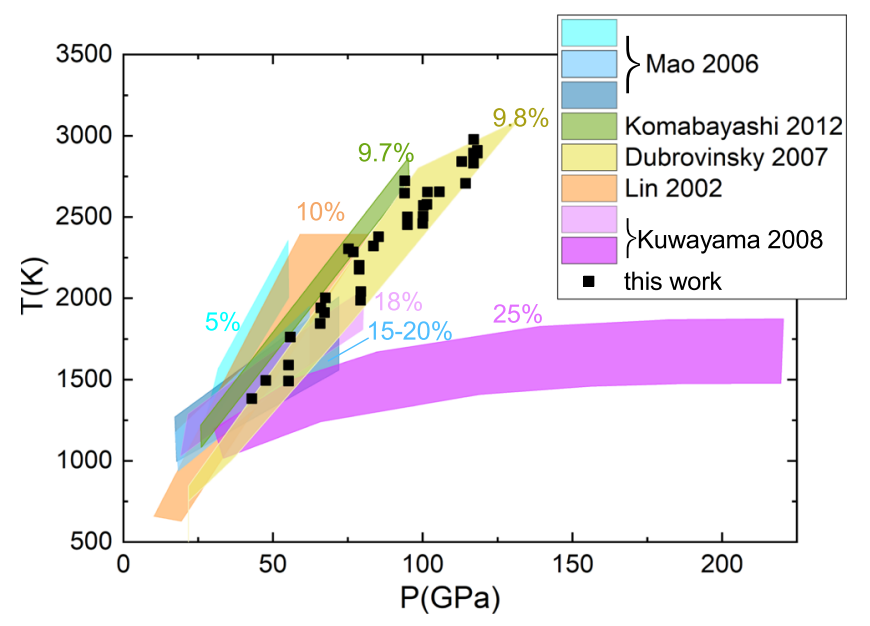

Figure 3. The hcp/fcc boundary found in this study for Fe-20wt\%Ni and comparison to other experimental works at close compositions (as indicated next to the corresponding shaded area). $T$ and $P$ errors are around $10 \%$ of the measured values.
We report hcp/fcc coexistence data in Figure 3 in comparison with previous experimental works. Our results extend the hcp/fcc boundary of Fe-20wt\%Ni up to $3000 \mathrm{~K}$ and $120 \mathrm{GPa}$. The Clapeyron slope (dT/dP) for the hcp/fcc boundary is found to be steeper with respect to previous studies at similar Ni content (Kuwayama et al., 2008; Mao et al., 2006) and closer to previously reported boundary for Fe-10wt\%Ni (Dubrovinsky et al., 2007). Komabayashi and coauthors (Komabayashi et al., 2012) claim that differences in the phase boundaries reported for Fe-10wt\% Ni can be explained in terms of different evaluation or neglecting of the thermal pressure. This could also apply to the Fe-20wt\%Ni case even though it does not explain all the discrepancies. In the work of Kuwayama et al. (2008) the pressure at high $T$ was determined using the PVT equation of $\mathrm{MgO}$ and could be overestimated by $8 \mathrm{GPa}$ at most because of axial temperature gradients. In the work of Mao et al. (2006), the thermal pressure was neglected; therefore, a steeper slope would be expected.

The previous results on the hcp/fcc boundary in Fe rich Fe-Ni alloys shown in Figure 3 have been used to formulate important hypothesis on the structure of the Earth's inner core (IC, 330-364 GPa and 4000 - $7000 \mathrm{~K}$; Anzellini et al., 2013), mostly proposing iron rich Fe-Ni alloys to crystallize in the hcp phase (Komabayashi et al., 2012; Lin et al., 2002; Mao et al., 2006; Sakai et al., 2014; Tateno et al., 2012). A simple extrapolation of our hcp/fcc boundary supports the hypothesis of the hcp structure for Fe-Ni with $20 \mathrm{wt} \%$ of $\mathrm{Ni}$ at IC conditions, and the same would apply to lower Ni contents.

The temperature-induced transition to the liquid phase can also be clearly distinguished in the XANES region. As temperature is increased, the two peaks (B in Figure 2, right panel) get suppressed while the shoulder shape flattens (A). Similar changes are observed at different pressures for the two alloys. The melting detection with XANES has been recently applied to determine the melting curves of pure $\mathrm{Ni}$ (Boccato et al., 2017) and pure Fe (Morard et al., 2018). This method has been validated by scanning electron microscope (SEM) textural analyses, performed on exposed transverse sections of samples recovered from the in situ experiments, and theoretical calculations in the case of pure Co (Boccato, 2017).

In order to avoid any data misinterpretation due to modifications in the sample assembly after melting, that is, sample diffusion and/or chemical reactions, only the first appearance of mix or full liquid phase was considered for the melting curve determination, and each heating run has been performed on a fresh portion of the sample. Chemical reactions with carbon and oxygen are clearly detectable through modifications in the XANES (Aprilis et al., 2019; Boccato et al., 2020) and have been monitored by acquiring a quench (cold) spectrum in between each increase of laser power (see the supporting information).

The Fe-20wt\%Ni melting curve, obtained using a Simon-Glatzel fit (Simon \& Glatzel, 1929) of the first liquid (or mixtures) data, reported in the phase diagram in Figure 4, almost superimposes on the pure Fe one up to $100 \mathrm{GPa}$. The Fe melting curve reported by Morard et al. (2018) combines results of XANES, XRD (Anzellini et al., 2013), and results of SMS (Jackson et al., 2013; Zhang et al., 2016). The negligible effect of Ni is in agreement with a previous Fe-Ni study (Zhang et al., 2016); the discrepancies of the absolute values, in fact, is given by a different estimate of the thermal pressure (Morard et al., 2018). A kink of the melting line of Fe-20wt\% Ni can be also expected in correspondence to the triple point, as in pure Fe (Morard et al., 2018). Therefore, an extrapolation of this melting curve to IC boundary conditions would not be reliable, and measurements above $120 \mathrm{GPa}$, where the melting occurs from the hcp phase, are needed.

Three heating runs, at 30, 50, and $60 \mathrm{GPa}$, were performed on the Fe-Ni alloy with $36 \mathrm{wt} \%$ of Ni. For the sake of clarity, only the first melting signatures are reported on the phase diagram for this alloy. These three melting points nicely overlap on the Fe-20wt\%Ni melting curve, indicating that even higher Ni content does not affect the melting curve of Fe, differently from the effect of light elements alloying (Morard et al., 2017).

The hcp/fcc boundary is fitted linearly. The extrapolation of the melting curve and of the hcp/fcc phase boundary from $120 \mathrm{GPa}$ allows to locate the hcp/fcc/liquid triple point of Fe-20wt\%Ni at $170 \pm 20 \mathrm{GPa}$ and $4000 \pm 400 \mathrm{~K}$. For pure Fe, the triple point has been recently found at $100 \pm 10 \mathrm{GPa}$ and 


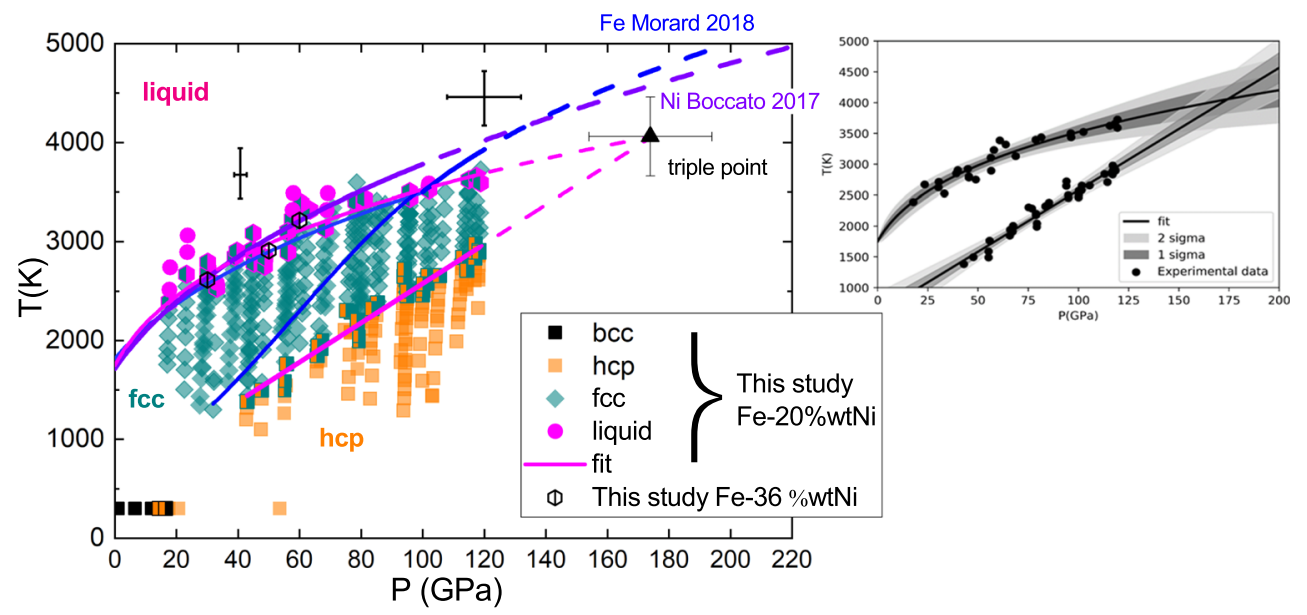

Figure 4. Left: phase diagram obtained from the experimental data. Black, orange, and cyan rotated squares are bcc, hcp, and fcc solid phases, respectively. The bcc/hcp and hcp/fcc coexistence range is indicated as two-color squares. Pink circles indicate liquid phases, and two-color (pink and green) hexagons are solid-liquid mixtures. The black triangle represents the predicted position for the hcp/fcc/liquid triple point of Fe-20wt\%Ni. Black hexagonal symbols represent melting points for the Fe-36wt\%Ni alloy. Black crosses represent $\mathrm{P} / \mathrm{T}$ errors for the melting points in different pressure regions of the phase diagram and have been shifted in vertical for clarity. The melting curves of pure Fe from Morard et al. (2018) and pure Ni from Boccato et al. (2017) are also shown. Right: phase boundaries incertitude evaluated as described in Text S7.

$3500 \pm 200 \mathrm{~K}$ (Morard et al., 2018). Therefore, while the melting curve of fcc Fe is substantially unaffected by the addition of $20 \mathrm{wt} \%$ of $\mathrm{Ni}$, because of the shift of the hcp/fcc boundary, the triple point moves significantly to higher pressures and temperatures.

The position of the triple point is important for thermodynamic modeling (Komabayashi \& Fei, 2010) or to constrain entropy change upon melting related to heat flow at the core-mantle boundary (CMB) (Anderson, 1990). Our results allow constraining the position of the triple point for a geophysical pertinent composition, Fe-10wt\% Ni, by assuming melting curve similar to pure Fe and Fe-20wt\%Ni in the fcc phase, and a linear variation of the hcp/fcc boundary with Ni content, which is also in agreement with most recent measurements of the hcp/fcc boundary by Komabayashi et al. (2012) (Figure 5, left panel). The position of the triple
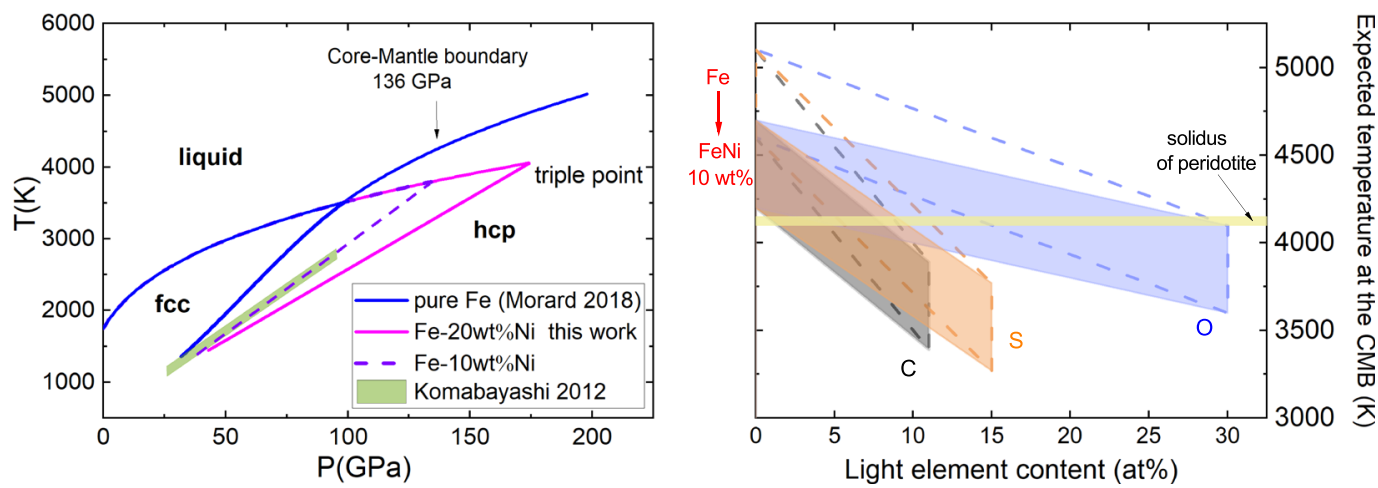

Figure 5. Left: schematic evolution of Fe-Ni phase diagram as a function of Ni content. The addition of Ni does not affect the melting curve in the fcc structure, but the triple point hcp-fcc-liquid is shifting toward higher pressure and temperature. Right: expected temperature at the CMB for a core with Fe-X (dashed areas) and FeNi-X (full colored areas) composition, where $\mathrm{X}$ is $\mathrm{C}, \mathrm{S}$, or $\mathrm{O}$. The temperature at $\mathrm{CMB}$ is higher than the crystallization temperature of the outercore alloy by 400-900 K (Anzellini et al., 2013; Komabayashi, 2014) since across the liquid outer core (from 135 to $330 \mathrm{GPa}$ ) the geotherm is expected to follow an adiabat with $P$ - $T$ slope that is less steep than the melting curve (otherwise, the outercore would not be liquid). Therefore, this is estimated to be $4600-5100 \mathrm{~K}$ for pure Fe and $4200-4700 \mathrm{~K}$ for Fe-Ni. 
point for Fe-10wt\% Ni is then expected around $135 \mathrm{GPa}$ and $3800 \mathrm{~K}$ and indicates a reduction of the melting temperature at $\mathrm{CMB}$ conditions by around $400 \mathrm{~K}$ with respect to pure Fe. This impacts the liquidus for $\mathrm{Fe}$ alloys constituting the Earth's core, by shifting it toward lower temperature. As pure Fe has a melting temperature comparable to mantle silicates at CMB pressure ( 4200 K), Ni addition will reduce this to $\sim 3800 \mathrm{~K}$.

In a previous discussion, we have shown that the presence of a notable amount of light elements is required to lower the crystallization temperature of core materials at CMB below $4150 \mathrm{~K}$ (Figure 7 in Morard et al., 2017), an upper bound that corresponds to the mantle melting temperature at $136 \mathrm{GPa}$ (Andrault et al., 2011; Fiquet et al., 2010) (Figure 5, right panel). The observation that the main constituting alloy (Fe-Ni) in the core exhibits already a reduced melting temperature suggests that a lower fraction of light elements is required. Such a low fraction is in better agreement with the one estimated from geochemical observations and the one required to reduce the density (and seismic wave speed) of the core (Badro et al., 2014).

\section{Conclusions}

In this study we present the first experimental determination of melting curves of Fe-Ni alloys at 20 and $36 \mathrm{wt} \%$ of Ni by means of X-ray absorption spectroscopy in the laser heated DAC, as well as their highpressure, high-temperature phase diagram in the solid phase in the 0-120 GPa and 300-3500 K range. Our data allow locating the position of the hcp/fcc/liquid triple point for Fe-20wt\%Ni at $170 \pm 20 \mathrm{GPa}$ and $4000 \pm 400 \mathrm{~K}$.

Our results indicate that while Ni alloying with Fe strongly modifies the equilibrium relations of the hcp and fcc phases, by enlarging the fcc stability domain, the $P$-induced bcc/hcp transition (at ambient $T$ ) and the melting curve up to $1 \mathrm{Mbar}$ are substantially unaffected. On the other hand, the shift of the hcp/fcc/liquid triple point has important consequences for $\mathrm{Fe}-\mathrm{Ni}$ alloys at concentrations relevant for Earth interior $(10 \mathrm{wt} \% \mathrm{Ni}$ ) as it implies a reduction of the melting temperature of around $400 \mathrm{~K}$ at $\mathrm{CMB}$ with respect to pure $\mathrm{Fe}$, thus shifting the whole liquidus for Fe alloys constituting the Earth's core toward lower temperature. This, is turn, has important consequences on the core composition requiring a lower amount of light elements than previously predicted.

\section{Data Availability Statement}

Data are available on Zenodo (Torchio et al., 2020) with free academic licence.

\section{References}

Anderson, O. L. (1990). The high-pressure triple points of iron and their effects on the heat flow from the Earth's core. Journal of Geophysical Research, 95(B13), 21,697-21,707. https://doi.org/10.1029/JB095iB13p21697

Andrault, D., Bolfan-Casanova, N., Nigro, G. L., Bouhifd, M. A., Garbarino, G., \& Mezouar, M. (2011). Solidus and liquidus profiles of chondritic mantle: Implication for melting of the earth across its history. Earth and Planetary Science Letters, 304(1), 251-259. https:// doi.org/10.1016/j.epsl.2011.02.006

Anzellini, S., Dewaele, A., Mezouar, M., Loubeyre, P., \& Morard, G. (2013). Melting of iron at Earth's inner core boundary based on fast X-ray diffraction. Science, 340(6131), 464-466.

Aprilis, G., Kantor, I., Kupenko, I., Cerantola, V., Pakhomova, A., Collings, I. E., et al. (2019). Comparative study of the influence of pulsed and continuous wave laser heating on the mobilization of carbon and its chemical reaction with iron in a diamond anvil cell. Journal of Applied Physics, 125(9), 095901. https://doi.org/10.1063/1.5067268

Badro, J., Cote, A. S., \& Brodholt, J. P. (2014). A seismologically consistent compositional model of Earth's core. Proceedings of the National Academy of Sciences, 111(21), 7542-7545.

Barge, N. V., \& Boehler, R. (1990). Effect of non-hydrostaticity on the $\alpha-\epsilon$ transition of iron. High Pressure Research, 6(2), 133-140. https:// doi.org/10.1080/08957959008203204

Benedetti, L., \& Loubeyre, P. (2004). Temperature gradients, wavelength-dependent emissivity, and accuracy of high and very-high temperatures measured in the laser-heated diamond cell. High Pressure Research, 24(4), 423-445.

Birch, F. (1952). Elasticity and constitution of the Earth's interior. Journal of Geophysical Research, 57(2), $227-286$.

Boccato, S. (2017). Local structure of liquid 3D metals under extreme conditions of pressure and temperature (Ph.D. Thesis).

Boccato, S., Torchio, R., Anzellini, S., Boulard, E., Guyot, F., Irifune, T., et al. (2020). Melting properties by X-ray absorption spectroscopy: Common signatures in binary Fe-C, Fe-O, Fe-S and Fe-Si systems. Scientific Reports, https://doi.org/10.1038/s41598-020-68244-3

Boccato, S., Torchio, R., Kantor, I., Morard, G., Anzellini, S., Giampaoli, R., et al. (2017). The melting curve of nickel up to 100 GPa explored by XAS. Journal of Geophysical Research: Solid Earth, 122, 9921-9930. https://doi.org/10.1002/2017JB014807

Buchwald, V. F. (1975). Handbook of iron meteorites: Their history, distribution, composition and structure.

Dewaele, A., Torrent, M., Loubeyre, P., \& Mezouar, M. (2008). Compression curves of transition metals in the Mbar range: Experiments and projector augmented-wave calculations. Physical Review B - Condensed Matter and Materials Physics, 78(10), 104102. https://doi.org/ 10.1103/PhysRevB.78.104102

Dubrovinsky, L. S., Dubrovinskaia, N. A., Narygina, O., Kantor, I., Kuznetsov, A. Y., Prakapenka, V. B., et al. (2007). Body-centered cubic iron-nickel alloy in Earth's core. Science, 316, 1880-1884. 
Fiquet, G., Auzende, A. L., Siebert, J., Corgne, A., Bureau, H., Ozawa, H., \& Garbarino, G. (2010). Melting of peridotite to 140 gigapascals. Science, 329(5998), 1516-1518. https://doi.org/10.1126/science.1192448

Giampaoli, R., Kantor, I., Mezouar, M., Boccato, S., Rosa, A. D., Torchio, R., et al. (2018). Measurement of temperature in the laser heated diamond anvil cell: Comparison between reflective and refractive optics. High Pressure Research, 38(3), $250-269$.

Hirose, K., Labrosse, S., \& Hernlund, J. (2013). Composition and state of the core. Annual Review of Earth and Planetary Sciences, 41(1), 657-691. https://doi.org/10.1146/annurev-earth-050212-124007

Huang, E., Bassett, W. A., \& Weathers, M. S. (1988). Phase relationships in Fe-Ni alloys at high pressures and temperatures. Journal of Geophysical Research, 93(B7), 7741-7746. https://doi.org/10.1029/JB093iB07p07741

Huang, E., Bassett, W. A., \& Weathers, M. S. (1992). Phase diagram and elastic properties of Fe 30\% Ni alloy by synchrotron radiation. Journal of Geophysical Research, 97(B4), 4497-4502. https://doi.org/10.1029/92JB00020

Jackson, J. M., Sturhahn, W., Lerche, M., Zhao, J., Toellner, T. S., Alp, E. E., et al. (2013). Melting of compressed iron by monitoring atomic dynamics. Earth and Planetary Science Letters, 362, 143-150. https://doi.org/10.1016/j.epsl.2012.11.048

Kantor, I., Marini, C., Mathon, O., \& Pascarelli, S. (2018). A laser heating facility for energy-dispersive X-ray absorption spectroscopy. Review of Scientific Instruments, 89(013111), 1-13.

Komabayashi, T. (2014). Thermodynamics of melting relations in the system Fe-FeO at high pressure: Implications for oxygen in the Earth's core. Journal of Geophysical Research: Solid Earth, 119, 4164-4177. https://doi.org/10.1002/2014JB010980

Komabayashi, T., \& Fei, Y. (2010). Internally consistent thermodynamic database for iron to the Earth's core conditions. Journal of Geophysical Research, 115, B03202. https://doi.org/10.1029/2009JB006442

Komabayashi, T., Hirose, K., \& Ohishi, Y. (2012). In situ X-ray diffraction measurements of the fcc-hcp phase transition boundary of an Fe-Ni alloy in an internally heated diamond anvil cell. Physics and Chemistry of Minerals, 39, 329-338.

Kuwayama, Y., Hirose, K., Sata, N., \& Ohishi, Y. (2008). Phase relations of iron and iron-nickel alloys up to $300 \mathrm{GPa}$ : Implications for composition and structure of the Earth's inner core. Earth and Planetary Science Letters, 273(3-4), 379-385. https://doi.org/10.1016/j. epsl.2008.07.001

Lin, J.-F., Heinz, D. L., Campbell, A. J., Devine, J. M., Mao, W. L., \& Shen, G. (2002). Iron-nickel alloy in the Earth's core. Geophysical Research Letters, 29(10), 1471. https://doi.org/10.1029/2002GL015089

Mao, W. L., Campbell, A. J., Heinz, D. L., \& Shen, G. (2006). Phase relations of FeNi alloys at high pressure and temperature. Physics of the Earth and Planetary Interiors, 155(1), 146-151. https://doi.org/10.1016/j.pepi.2005.11.002

Mao, H. K., Wu, Y., Chen, L. C., Shu, J. F., \& Jephcoat, A. P. (1990). Static compression of iron to $300 \mathrm{GPa}$ and $\mathrm{Fe}_{0.8} \mathrm{Ni}_{0.2}$ alloy to $260 \mathrm{GPa}$ : Implications for composition of the core. Journal of Geophysical Research, 95(B13), 21,737-21,742. https://doi.org/10.1029/ JB095iB13p21737

Morard, G., Andrault, D., Antonangeli, D., Nakajima, Y., Auzende, A. L., Boulard, E., et al. (2017). Fe-FeO and Fe-Fe ${ }_{3} \mathrm{C}$ melting relations at Earth's core-mantle boundary conditions: Implications for a volatile-rich or oxygen-rich core. Earth and Planetary Science Letters, 473, 94-103.

Morard, G., Boccato, S., Rosa, A., Anzellini, S., Miozzi, F., Henry, L., et al. (2018). Solving controversies on the iron phase diagram under high pressure. Geophysical Research Letters, 45, 11,074-11,082. https://doi.org/10.1029/2018GL079950

Pascarelli, S., Mathon, O., Mairs, T., Kantor, I., Agostini, G., Strohm, C., et al. (2016). The Time-resolved and Extreme-conditions XAS (TEXAS) facility at the European Synchrotron Radiation Facility: The energy-dispersive X-ray absorption spectroscopy beamline ID24. Journal of Synchrotron Radiation, 23(1), 353-368.

Poirier, J.-P. (1994). Light elements in the Earth's outer core: A critical review. Physics of the Earth and Planetary Interiors, 85(94), 319-337.

Reagan, M. M., Gleason, A. E., Liu, J., Krawczynski, M. J., Orman, J. A. V., \& Mao, W. L. (2018). The effect of nickel on the strength of iron nickel alloys: Implications for the earths inner core. Physics of the Earth and Planetary Interiors, 283, 43-47. https://doi.org/10.1016/j. pepi.2018.08.003

Rosa, A. D., Mathon, O., Torchio, R., Jacobs, J., Pasternak, S., Irifune, T., \& Pascarelli, S. (2019). Nano-polycrystalline diamond anvils: Key devices for XAS at extreme conditions: Their use, scientific impact, present status and future needs. High Pressure Research, $40,1-17$. https://doi.org/10.1080/08957959.2019.1700978

Sakai, T., Takahashi, S., Nishitani, N., Mashino, I., Ohtani, E., \& Hirao, N. (2014). Equation of state of pure iron and $\mathrm{Fe}_{0.9} \mathrm{Ni}_{0.1}$ alloy up to 3 Mbar. Physics of the Earth and Planetary Interiors, 228, 114-126. https://doi.org/10.1016/j.pepi.2013.12.010

Simon, F., \& Glatzel, G. (1929). Bemerkungen zur Schmelzdruckkurve. Zeitschrift fur Anorganische und Allgemeine Chemie, 178, 309-316.

Tateno, S., Hirose, K., Komabayashi, T., Ozawa, H., \& Ohishi, Y. (2012). The structure of Fe-Ni alloy in Earth's inner core. Geophysical Research Letters, 39, L12305. https://doi.org/10.1029/2012GL052103

Torchio, R., Boccato, S., Miozzi, F., Rosa, A. D., Ishimatsu, N., Kantor, I., et al. (2020). Melting curve and phase relations of Fe-Ni alloys at high pressure and high temperature: Implications for the Earth core composition. Zenodo. https://doi.org/10.5281/zenodo.3725624

Zhang, D., Jackson, J. M., Zhao, J., Sturhahn, W., Alp, E. E., Hu, M. Y., et al. (2016). Temperature of Earth's core constrained from melting of $\mathrm{Fe}$ and $\mathrm{Fe}_{0.9} \mathrm{Ni}_{0.1}$ at high pressures. Earth and Planetary Science Letters, 447, 72-83. https://doi.org/10.1016/j.epsl.2016.04.026 